\title{
Binocular Visual Function in a Pre-Presbyopic Patient with Uniocular Cataract Undergoing Cataract Surgery with a Multifocal Intraocular Lens
}

This article was published in the following Dove Press journal: Clinical Ophthalmology

\section{Laura J Wood (1D ${ }^{1,2, *}$ \\ Jasleen $\mathrm{K}$ Jolly (D) ${ }^{1,2, *}$ \\ Markus Groppe 3 \\ Larry Benjamin ${ }^{3}$ \\ James F Kirwan ${ }^{4}$ \\ Nishal Patel ${ }^{5}$ \\ Mostafa A Elgohary ${ }^{6}$ \\ Robert E MacLaren ${ }^{1,2}$}

'Nuffield Laboratory of Ophthalmology, Nuffield Department of Clinical Neurosciences, University of Oxford, Oxford, UK; ${ }^{2}$ Oxford Eye Hospital, Oxford University Hospitals NHS Foundation Trust, Oxford, UK; ${ }^{3}$ Stoke Mandeville Hospital, Buckingham Healthcare NHS Trust, Walton, UK; ${ }^{4}$ Queen Alexandra Hospital, Portsmouth Hospitals NHS Trust, Portsmouth, UK;

${ }^{5}$ Kent and Canterbury Hospital, East Kent Hospitals University NHS Foundation Trust, Canterbury, UK; ${ }^{6}$ Kingston Hospital, Kingston Hospital NHS Foundation Trust, Kingston Upon Thames, UK

*These authors contributed equally to this work
Correspondence: Laura J Wood Nuffield Laboratory of Ophthalmology, Nuffield Department of Clinical Neurosciences, University of Oxford, Oxford, UK

Email enquires@ndcn.ox.ac.uk
Background/Aim: An increasing number of pre-presbyopic patients are undergoing uniocular cataract extraction. We aim to compare the binocular status of subjects with uniocular cataracts, implanted either with a multifocal or a monofocal intraocular lens (IOL).

Materials and Methods: Subjects were recruited from outpatient ophthalmology clinics and randomized to an IOL type. Corrected and uncorrected LogMAR distance visual acuity (VA) and near and intermediate VA using the Radner reading test were completed. The binocular tests included the Worth Four Dot Test, fixation disparity, TNO stereoacuity and foveal suppression assessment. In addition to the near activity vision questionnaire. The trial was closed early because the chosen multifocal lens had been superseded by newer models. We report two subjects, one receiving the multifocal IOL and a monofocal IOL control with the most comparable baseline characteristics.

Results: Both subjects experienced uncomplicated cataract surgery, showing clinically significant improved corrected distance VA, 0.06 LogMAR and -0.16 LogMAR in the monofocal and multifocal IOL, respectively. The multifocal subject had 30 seconds of arc stereoacuity indicating normal binocular vision. Only gross binocular single vision with no stereopsis was found in the monofocal IOL subject. The latter subject also had reduced near vision quality-of-life questionnaire results.

Conclusion: This two-patient case series demonstrates greater binocular near ability, with the multifocal IOL, in the pre-presbyopic patient undergoing uniocular cataract surgery. The case series highlights the need, and methodology for investigating further the functional and quality-of-life benefits of implanting multifocal IOLs in pre-presbyopic patients, those in their twenties and thirties, undergoing uniocular cataract surgery.

Keywords: binocular vision, cataracts, pseudophakia, multifocal intraocular lens, accommodation

\section{Plain Language Summary}

The case series describes the outcome of two subjects following cataract removal. One subject received a single focus (monofocal) artificial implanted lens, whilst the second subject received a multifocal artificial implanted lens, designed to give clear vision at both distance and near. The work had initially started out as a randomized interventional trial; however, it was terminated early as newer multifocal lens models had become available. We decided to present this case series to illustrate our methodology and findings in the light of future work.

The case series evaluated the effect of these implanted lenses on vision as well as how the subject's eyes work together. The monofocal implanted lens showed inferior near visual clarity and reduced depth perception, associated with increased problems with everyday near 

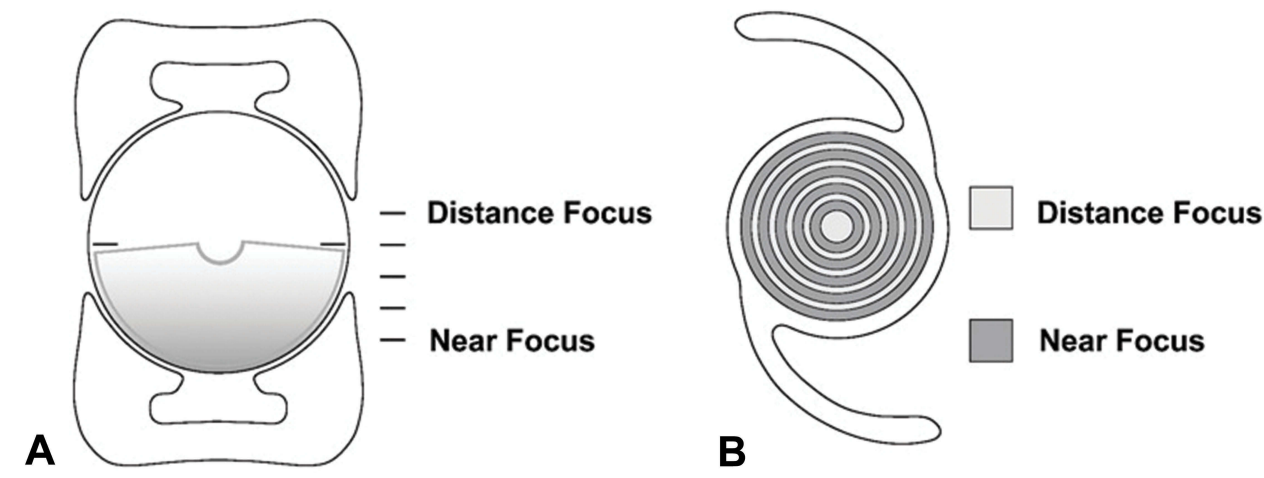

Figure I (A) Schematic diagram of the LENTIS MPlus LS-3I3 MF30 multifocal IOL, detailing the distance portion of the lens and the lower half of the lens containing the near focus, with a blended junction between the two. (B) Schematic diagram of a typical multifocal IOL based on a concentric distance and near ring zone design.

activities. In contrast, the multifocal implanted lens showed better intermediate and near vision, normal levels of depth perception and fewer difficulties with everyday near activities. The multifocal artificial lens appeared to complement the natural focusing of the untreated eye in order to restore normal near vision. Although the case series is too small to create widespread guidance, the results indicate a need and methodology for further investigation, using newer multifocal IOL designs.

\section{Introduction}

Cataracts are the worldwide leading cause of reversible blindness, ${ }^{1}$ typically due to the natural lens aging; however, other factors such as metabolic abnormalities, nutritional disorders, chronic ocular inflammation and trauma can predispose younger pre-presbyopic individuals to early cataract onset. ${ }^{2}$ In addition, vitreoretinal surgery has seen many advances in the last 40 years, this has led to the increased incidence of vitreoretinal procedures. ${ }^{3}$ Moreover, the advent of gene therapy in young patients with inherited retinal conditions such as choroideremia and X-linked retinitis pigmentosa involves vitrectomy and subretinal injection surgical procedures. ${ }^{4,5}$ Cataract is a known side effect of vitreoretinal surgery with a reported incidence of $85.5 \%$ within 5 years of the vitrectomy surgery. Of these, $50 \%$ occurred within the first year. ${ }^{6}$ These cataracts develop following the removal of the vitreous due to increased lens nucleus oxidation. Strategies to reduce vitreous oxygen levels and reduce cataract occurrence remain hypothetical. ${ }^{6}$ Therefore, improving postsurgery cataract management and cataract extraction outcomes are paramount.

Currently, only monofocal intraocular lenses (IOL) are available in the National Health Service (NHS) in the
United Kingdom as part of standard care. In other healthcare systems, multifocal IOLs will require greater justification due to the increased cost. This means prepresbyopic patients' prioritise their distance vision at the expense of their accommodation, affecting the treated eyes near vision ability and overall their near binocularity. This sacrifice significantly hinders near stereopsis and patient reported near visual function. ${ }^{7,8}$

Many studies have demonstrated improved near vision and near visual function with multifocal IOLs in presbyopic patients. ${ }^{9-12}$ However, to date, the effects of using a multifocal IOL to complement accommodative ability and near binocular visual function in a pre-presbyopic patient requiring only uniocular cataract surgery have not been formally assessed.

The LENTIS MPlus LS-313 MF30 multifocal IOL (Oculentis, Eerbeek, Netherlands) is a rotationally asymmetrical bifocal "multifocal" IOL design, with an aspheric distance lens and an inferiorly embedded near vision segment (providing a $+3.00 \mathrm{DS}$ add). The optical power transitions from distance to near, within the segment in order to avoid a sharp junction (Figure 1). ${ }^{12,13}$ The advantage of this approach is to avoid sharp borders, to reduce the haloes and glare stimuli, commonly experienced with multifocal IOLs. ${ }^{14}$

The monofocal IOL chosen for this study was the 4-point fixation haptic AKREOS ${ }^{\circledR}$ ADAPT AO (Bausch + Lomb, Montpellier France). This was chosen as it was the closest possible lens type comparable to the multifocal IOL, available across different NHS hospitals at the time the study commenced. Further, IOL details are shown in Table $1 .{ }^{15}$

Our aim was to determine the extent of binocular visual function, following uniocular IOL implantation, with both the monofocal and multifocal IOL, in pre-presbyopic subjects requiring cataract extraction surgery in one eye only. 
Table I The Properties of the Multifocal and Standard IOL Lenses Used in the Study

\begin{tabular}{|l|l|l|}
\hline & Lentis Mplus LS-3 I3 MF30 & AKREOS $^{\circledR}$ ADAPT AO \\
\hline Type & Foldable one-piece multifocal acrylic IOL & One piece, aberration free acrylic IOL \\
Optic Size (mm) & $6.0 \times 11.0$ & $6.0 / 6.2 \times 10.7 / I 1.0$ \\
Optic Design & Aspheric, square edges, posterior sector shaped near segment & Aspheric, square edge, four point fixation \\
& $+3.00 \mathrm{DS}$ & \\
Available Diopters (D) & $-10.0 \mathrm{D}$ to - I.0D (I.0D), $\pm 0.0 \mathrm{D}$ to $\pm 36.0 \mathrm{D}(0.5 \mathrm{D})$ & $0.0 \mathrm{D}$ to $+10.0 \mathrm{D}(\mathrm{I.0D}),+10.0 \mathrm{D}$ to $+30.0 \mathrm{D}(0.5 \mathrm{D})$ \\
Refractive Index & 1.46 & 1.46 \\
\hline
\end{tabular}

\section{Materials and Methods}

\section{Ethical Approval and Recruitment}

Oxford Eye Hospital, Stoke Mandeville Hospital, Kingston Hospital, Queen Alexandra Hospital and Kent and Canterbury Hospital participated in this ethics approved prospective randomized control trial. Subjects were recruited from NHS clinics following approval by the research ethics committee (NCT01872000) and conducted in accordance with the Declaration of Helsinki 2013. The trial had intended to recruit and randomize more subjects however, it was closed early due to slow recruitment and because the chosen multifocal lens had been superseded by newer IOL models. ${ }^{16,17}$ Five subjects had completed the trial by termination; however, as a consequence of randomisation, four of these subjects had been randomised to control, receiving a monofocal IOL, only one subject received the multifocal IOL. The control participant with the baseline characteristics most alike the subject participant was selected for analyses in this case series.

\section{Preoperative Inclusion and Exclusion Criteria}

The recruited subjects had to be of pre-presbyopic age and have no history of ocular surgery, as well as no other ophthalmic pathology, squint or amblyopia, or corneal astigmatism greater than $1.00 \mathrm{DC}$, and required an IOL power range of between 10-30D. Cataract type or aetiology was not a controlled factor. The subject's fellow eye had to have VA of at least $6 / 9$ and predicted visual improvement in the treated eye of at least 6/12.

\section{Randomization and Allocation Concealment}

The subjects were randomized, to either the Lentis MPlus LS-313 MF30 multifocal or the monofocal aspheric 4-point fixation haptic IOL, using the Microsoft Excel "RAND" function. This was administrated by a research staff member not associated with this work, to enable the investigating optometrist and patient to remain masked to the IOL type used for the duration of the study. The surgeon was informed about the lens allocation at the time of surgery to avoid the patient being informed by the surgeon ahead of time which lens they were receiving.

\section{Surgical Procedure and Postoperative Follow-Up}

The subjects underwent standard phacoemulsification cataract surgery. The case series had no influence on the specifics of the surgical procedure. Following surgery, the subjects were seen at 1 week and 6 weeks as per routine care. An additional visit was arranged between 3 and 6 months following surgery for the final assessment visit. This timescale was chosen to allow the subject time to settle and adapt to their new lens and spectacle correction if required, enabling the measurement to reflect final visual function.

\section{Postoperative Visual Assessment}

The visual assessments conducted at baseline and visit five, listed below, were performed in a carefully planned order so as to progressively assess the depth of binocularity.

\section{Visual Acuity}

All distance VA tests were assessed using the Early Treatment Diabetic Retinopathy Study (ETDRS) chart, performed at $4 \mathrm{~m}$. These measurements included unaided distance VA and best distance corrected distance VA. Intermediated and near VA were assessed with the Radner reading charts at $67 \mathrm{~cm}$ and $30 \mathrm{~cm}$, respectively, using the standardised Radner test methodology. ${ }^{18}$ This included unaided intermediate VA, best distance corrected intermediate VA, unaided near VA, best distance corrected near VA and best near corrected VA. 


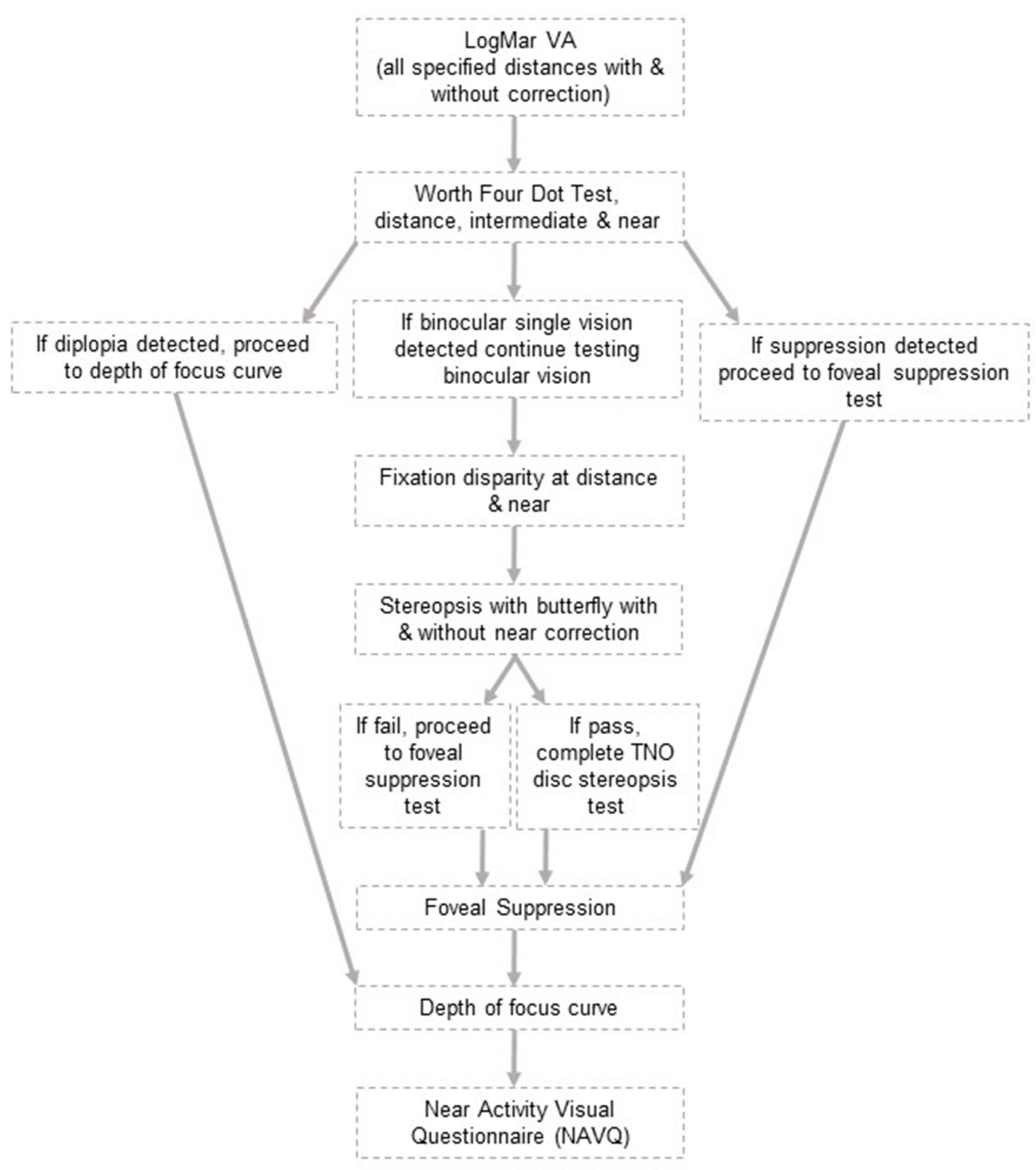

Figure 2 The order of testing and the optimised test procedures depending on the subject's binocular vision status and level of stereopsis.

\section{Suppression}

The Worth Four Dot Test was used to assess for monocular suppression at distance $(6 \mathrm{~m})$, intermediate distance $(67 \mathrm{~cm})$ and at near $(33 \mathrm{~cm})$, both with and without a near addition lens placed in front the operated eye. ${ }^{19}$ Figure 2 shows the progression of testing depending upon the outcome of the Worth Four Dot Test. 


\section{Fixation Disparity}

Fixation disparity test measures small ocular misalignment under the conditions of binocular single vision, it was performed at both distance $(6 \mathrm{~m})$ and near $(33 \mathrm{~cm})$ with a mallet unit. The amount of aligning prism required to neutralize any misalignment in both horizontal and vertical directions was recorded. ${ }^{20}$

\section{Stereopsis}

Gross stereopsis was assessed using the TNO butterfly test at a viewing distance of $40 \mathrm{~cm}$ both with and without a $+2.50 \mathrm{DS}$ near add. The results were recorded as either pass or fail on plate one, depending on whether one or two butterflies were seen. To measure the level of stereopsis the disc TNO stereo test was applied beginning at plate five. ${ }^{21}$ The subjects were encouraged to identify the missing shape until they had two consecutive incorrect answers, the last correct answer was recorded as the stereoacuity.

\section{Foveal Suppression}

A panel on the top of the near Mallet unit was used to test for foveal suppression, at the subject's habitual reading distance and with the subject's habitual near addition. ${ }^{22}$ The number of letters seen was recorded each time. To calculate the percentage of foveal suppression, a ratio scoring method was applied using the number of letters read with dichoptic viewing while binocularly fused (b) and under monocular $(\mathrm{m})$ conditions. The following formula was applied:

$$
\text { Foveal suppression } \%=100 \times \frac{(m-b)}{m}
$$

By using polarizing filters to maintain binocular fusion whilst dissociating the eyes, healthy subjects should be able to read more letters in monocular conditions than binocular conditions due to the presence of foveal suppression. ${ }^{22}$

\section{Depth of Focus}

To assess the range of neurological and perceptual tolerances of the subjects' visual system, the depth of focus was assessed monocularly. ${ }^{23}$ Using the ETDRS charts R, one and two, at $4 \mathrm{~m}$, with the subjects distance correction in place and the contralateral eye occluded, lens powers ranging from +3.00DS to $-4.00 \mathrm{DS}$ in $0.50 \mathrm{D}$ steps were presented in front of the eye in a random order. The logMAR VA was recorded for each lens presentation. The test charts were presented in a randomly rotated order to prevent learning of the letters. These results were used to create a defocus curve, to illustrate the depth of focus for each eye for each subject.

\section{NAVQ Questionnaire}

Subjective change in vision was assessed using the validated Near Activity Vision Instrument Questionnaire (NAVQ) developed in 2012. ${ }^{24}$ This was designed to assess and grade the difficulty of specific near activities that are reflective of daily life. The subject had to specify whether they found the activity to be of no difficulty, of little difficulty, moderate difficulty or extreme difficulty. No difficulty scores zero and the score increases stepwise until extreme difficulty scoring three. The sum of the scores determines the overall difficulty experienced, the higher the result, the more problems the subject experiences. $^{24}$

\section{Results}

Two subjects with comparable baseline characteristics, including age, pupil sizes and pre-surgery refraction, detailed in Table 2, underwent uncomplicated cataract surgery and showed clinically significant improved corrected distance VA at the final visit, visit five. Intermediate vision with the multifocal IOL was maintained at visit five, whilst the near VA with the multifocal IOL improved. This is in comparison to the monofocal IOL, where both the intermediate and near VA deteriorated at visit five (Table 3).

\section{Global Suppression and Fixation Disparity} Both participants had no signs of suppression or diplopia with the Worth Four Dot Test at all distances with and without corrections. This demonstrates the presence of gross binocular single vision. No distance or near fixation disparity was found with either subject indicating intact ocular muscle alignment.

Table 2 Subject Demographics and Baseline Parameters

\begin{tabular}{|l|l|l|}
\hline & $\begin{array}{l}\text { Multifocal IOL } \\
\text { Subject }\end{array}$ & $\begin{array}{l}\text { Standard IOL } \\
\text { Subject }\end{array}$ \\
\hline Subject age (years) & 40 & 44 \\
$\begin{array}{l}\text { Pre-surgery refraction } \\
\text { (dioptres) }\end{array}$ & +0.25 & $+0.25 /-0.25 \times 170$ \\
IOL power (dioptres) & +18.50 & +21.50 \\
Right horizontal pupil & 4.5 & 4.0 \\
diameter (mm) & & 4.0 \\
Left horizontal pupil & 5.0 & \\
diameter (mm) & & \\
\hline
\end{tabular}


Table 3 Shows the Baseline and Postoperative VA Results in LogMAR/LogRAD

\begin{tabular}{|c|c|c|c|c|}
\hline & \multicolumn{2}{|l|}{ Visit I } & \multicolumn{2}{|l|}{ Visit 5} \\
\hline & Standard IOL & Multifocal IOL & Standard IOL & Multifocal IOL \\
\hline Unaided distance VA & 0.26 & 0.34 & 0.36 & 0.00 \\
\hline Unaided intermediate VA & - & - & 0.80 & 0.00 \\
\hline Unaided near VA & 0.30 & 0.25 & 0.90 & 0.10 \\
\hline Best distance corrected VA & 0.16 & 0.22 & 0.06 & -0.16 \\
\hline Best distance corrected intermediate VA & 0.30 & 0.20 & 0.70 & 0.20 \\
\hline Best distance corrected near VA & 0.30 & 0.25 & 0.90 & 0.10 \\
\hline
\end{tabular}

\section{Stereopsis}

The monofocal IOL subject was unable to accurately identify the number of butterflies on the TNO butterfly test, despite retesting with a +2.50DS near correction to compensate for any near blurring effect. Whereas the multifocal IOL subject passed the TNO butterfly test and revealed 30 seconds of arc stereoacuity with the TNO disc test, this reduced dramatically to 120 seconds of arc with the addition of a +2.50DS lens in front of the treated eye as would be expected, confirming the presence of pseudo-accommodation.

Table 4 Standard and Multifocal IOL Binocular Assessment Results at Visit 5

\begin{tabular}{|c|c|c|}
\hline Binocular Vision Assessment & $\begin{array}{l}\text { Standard } \\
\text { IOL }\end{array}$ & $\begin{array}{l}\text { Multifocal } \\
\text { IOL }\end{array}$ \\
\hline Distance Worth Four Dot Test $(6 \mathrm{~m})$ & BSV & BSV \\
\hline $\begin{array}{l}\text { Intermediate Worth Four Dot Test } \\
\text { unaided }(67 \mathrm{~cm})\end{array}$ & BSV & BSV \\
\hline $\begin{array}{l}\text { Near Worth Four Dot Test unaided } \\
(33 \mathrm{~cm})\end{array}$ & BSV & BSV \\
\hline $\begin{array}{l}\text { Intermediate Worth Four Dot Test } \\
\text { with }+2.50 \mathrm{DS} \text { add }(67 \mathrm{~cm})\end{array}$ & BSV & BSV \\
\hline $\begin{array}{l}\text { Near Worth Four Dot Test with } \\
+2.50 \mathrm{DS} \text { add }(33 \mathrm{~cm})\end{array}$ & BSV & BSV \\
\hline $\begin{array}{l}\text { Distance fixation disparity, horizontal/ } \\
\text { vertical }(6 \mathrm{~m})\end{array}$ & $0 / 0$ & $0 / 0$ \\
\hline $\begin{array}{l}\text { Near fixation disparity, horizontal/ } \\
\text { vertical }(33 \mathrm{~cm})\end{array}$ & $0 / 0$ & $0 / 0$ \\
\hline $\begin{array}{l}\text { TNO butterfly stereopsis test without } \\
\text { near }+2.50 \mathrm{DS} \text { add }\end{array}$ & Failed & Pass \\
\hline $\begin{array}{l}\text { TNO butterfly stereopsis test with } \\
\text { near }+2.50 \mathrm{DS} \text { add }\end{array}$ & Failed & Pass \\
\hline $\begin{array}{l}\text { TNO disc stereopsis test without near } \\
+2.50 \mathrm{DS} \text { add }\end{array}$ & NA & $\begin{array}{l}30 \text { seconds } \\
\text { of } \operatorname{arc}\end{array}$ \\
\hline $\begin{array}{l}\text { TNO disc stereopsis test with near } \\
+2.50 \mathrm{DS} \text { add }\end{array}$ & NA & $\begin{array}{l}120 \\
\text { seconds of } \\
\text { arc }\end{array}$ \\
\hline Foveal suppression with near mallet unit & $-11.76 \%$ & $21.05 \%$ \\
\hline NAVQ score (visit I score) & $26(20)$ & $3(14)$ \\
\hline
\end{tabular}

Abbreviation: BSV, binocular single vision.

\section{Foveal Suppression}

Foveal suppression assessments with the multifocal IOL showed that more letters were seen monocularly resulting in a foveal suppression of $21.5 \%$. Whereas with the monofocal IOL, an equal sum of letters were seen monocularly and binocularly, whilst fewer letters (particularly the smaller ones) were seen with the right eye (treated monofocal IOL eye), resulting in an abnormal negative suppression result $(-11.8 \%)$ (Table 4$)$.

\section{Depth of Focus}

The multifocal IOL showed a much larger depth of focus which was similar to the untreated eyes in both subjects. In comparison to the monofocal IOL that showed a steep decline in LogMAR VA with the addition of plus and minus lenses, indicating poor depth of focus (Figure 3).

\section{NAVQ Score results}

The NAVQ score improved by 11 (from 17 at visit one to 3 at visit five) with the multifocal IOL, with the subject reporting no difficulties apart from with very fine detail tasks such as painting nails. Whereas the monofocal IOL NAVQ score deteriorated by six (scoring 20 at visit one and 26 at visit five), with the subject reporting extreme difficulty with reading small print, seeing phone displays and generally conducting near work without correction.

\section{Discussion}

After successful cataract surgery in both subjects, normal binocular vision operated to fine degrees in the subject implanted with the multifocal IOL at both distance and near, with their stereopsis within normal limits. ${ }^{25}$ The subject with the monofocal IOL showed poor near vision, only gross binocular single vision and the absence of stereopsis, which was reflected in the deteriorated NAVQ results with the monofocal IOL. This suggests that the multifocal IOL was 


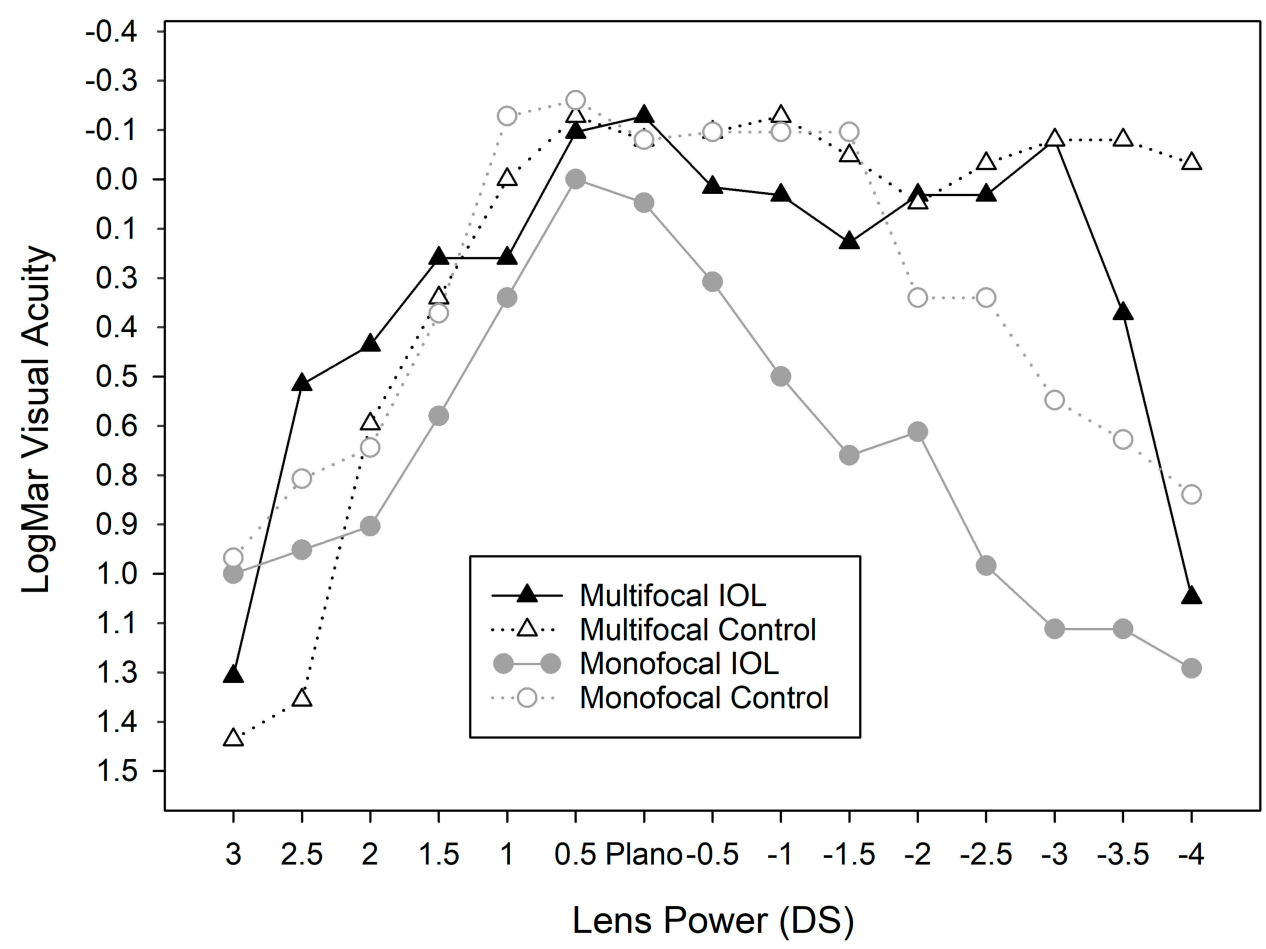

Figure 3 Depth of focus curve for both the multifocal IOL and monofocal IOL subject. The solid black line representing the multifocal IOL shows a greater depth of focus with the addition of minus powered lenses, compared with the solid grey line representing the monofocal IOL which demonstrates very poor focus depth.

able to complement the accommodative power of the untreated eye, whereas the monofocal IOL could not. The monofocal IOL did demonstrate slightly lower distance VA post-surgery (equivalent to $6 / 7.5^{+2}$ ), due to posterior capsular opacification; however, it was deemed not clinically significant.

The gross binocular vision indicated with the Worth Four Dot Test and fixation disparity showed that the ocular alignment required for binocular single vision, particularly at near, was not impaired by either IOL. Likewise, the global suppression assessments were not impaired by either IOL, indicating the absence of any neurological visual function defects.

The reduced stereopsis seen with the monofocal IOL indicates reduced visual function. Stereopsis can be affected by refractive blur; however, the addition of an uniocular spectacle add in front of the monofocal IOL did not improve the stereoacuity. This could be due to altered accommodation stimulation in the untreated contralateral eye. Alternatively, this could be due to aniseikonia, preventing the fusion of the retinal images, although this is unlikely as the add power was less than three dioptres. It has been reported that adults with anisometropic blur, due to monovision correction, either from long-term contact lens wear or surgical correction, develop a deficiency of foveal binocular vision. This leads to the development of permanent monofixation syndrome while the extrafoveal fusion reflex remains intact, the absence of foveal fusion manifests as reduced stereoacuity. ${ }^{26}$ These findings could extrapolate to pre-presbyopic patients, who require monocular cataract extraction and receive a monofocal IOL. Those patients would rely on their non-treated eye for near vision tasks and therefore may develop reduced foveal fixation or reduced near function in the treated eye. This would explain the reduced stereopsis results seen in our patient with the monofocal IOL, who had reduced stereoacuity even with a near add correction.

The trial was terminated early due to the selected multifocal IOL lens been superseded by newer models, preventing any clinical application conclusions. However, the case series demonstrates that the carefully selected methodology enabled an advanced understanding of binocular visual function in both subjects; using a range of tests to assess the muscular, neurological, optical and functional aspects of binocularity. The study methodology would provide a useful framework for future multifocal binocular visual function assessments.

The highly selective inclusion criteria were created to reduce the number of variables, to enable a more accurate 
representation of binocularity amongst the subjects. However, the impacts of these variables such as previous vitreoretinal surgery need to be addressed before clinical recommendations are made. Similarly, a patient's level of retinal visual function must be carefully considered, those with poorer quality of vision, such as reduced contrast sensitivity may struggle to adapt to the visual limitations of the multifocal IOL.

The known adverse effects of multifocal IOLs (including the LENTIS MPlus LS-313 MF30 multifocal IOL) such as increased glare, dysphotopsia, and visual distortions must be considered when counselling patients for a multifocal IOL. Although the multifocal subject in this case series did not report any major problems or adaptation difficulties. Careful lifestyle review is paramount to determine an individual's suitability for implantation of a multifocal IOL. The Lentis Mplus LS 313 was chosen as its +3.00DS near addition range could mimic the accommodative requirement for near vision. However, this may not be suitable for all patients, particularly those who spend a lot of time on tablet devices, reading music or on computers or simply prefer a longer reading distance. An IOL incorporating a lower power add may be more suitable in such patients; however, investigation is required to determine the effects of a lower near add on near binocular performance.

In addition, specific multifocal design suitability is imperative to this unique application. It must be stressed that many of the multifocal IOL's available would be unsuitable due to the effects of glare and haloes caused by sharp borders and the less natural near vision-generating zones, making neuro-adaptation very difficult.

\section{Conclusions}

This two-patient case series demonstrates binocular near ability with the multifocal IOL compared to the monofocal IOL, in a pre-presbyopic patient undergoing uniocular cataract surgery. The case series is too small for widespread guidance. It does highlight the need and methodology for investigating further the functional and quality-of-life benefits of implanting multifocal IOLs in pre-presbyopic patients, those in their twenties and thirties, undergoing uniocular cataract surgery. Particularly in light of advancing multifocal IOL technologies and improving vitreoretinal procedures and prognoses.

\section{Abbreviations}

BSV, binocular single vision; FD, fixation disparity; IOL, intraocular lens; VA, visual acuity; NAVQ, Near Activity Instrument Vision Questionnaire.

\section{Ethics Approval and Informed Consent}

The study was conducted in accordance with the principles of the Declaration of Helsinki 2013. The protocol, informed consent form, participant information sheet and any associated material was approved by the NRES Committee South Central - Oxford C Research Ethics Committee (Ethics reference 12/SC/0575). Informed consent was obtained from both study subjects separately for cataract surgery and participation in the study to ensure the patients did not feel participation in the study was necessary to obtain surgery.

\section{Consent for Publication}

Both subjects provided full consent to be part of the study and have their results published.

\section{Acknowledgments}

Laura J Wood and Jasleen K Jolly are co-first authors for this study. We would like to thank all the optometrists and nurses who aided the trial including Clare CouldridgeSmith, David Sculfor and Nicola Wood. Further thanks to those who coordinated the trial between centres, Ross Downes, Mini David, James Rand, Sarah Stirrup, Andrew Swain, Judith Abrams and Jennifer Crooks. Plus Laura Stacey for monitoring the randomization and Jonathan Brett for support with designing figure one.

The study was funded by part of an existing grant held by the Chief Investigator from the NIHR Oxford Biomedical Research Centre. The views expressed are those of the authors and not necessarily those of the NIHR or the Department of Health and Social Care. A further thank you to Oculentis and Bausch \& Lomb who provided the study lenses at reduced cost.

\section{Disclosure}

The authors report no conflicts of interest in this work.

\section{References}

1. Khairallah M, Kahloun R, Bourne R, et al. Number of people blind or visually impaired by cataract worldwide and in world regions, 1990 to 2010. Invest Ophthalmol Vis Sci. 2015;56(11):6762-6769. doi:10.1167/iovs.15-17201

2. Do DV, Gichuhi S, Vedula SS, et al. Surgery for post-vitrectomy cataract. Cochrane Database Syst Rev. 2013;12(12):CD006366.

3. El-Amir AN, Keenan TD, Abu-Bakra M, et al. Trends in rates of retinal surgery in England from 1968 to 2004: studies of hospital statistics. Br J Ophthalmol. 2009;93(12):1585-1590. doi:10.1136/ bjo.2009.159939 
4. Xue K, Jolly JK, Barnard AR, et al. Beneficial effects on vision in patients undergoing retinal gene therapy for choroideremia. Nat Med. 2018;24(10):1507-1512. doi:10.1038/s41591-018-0185-5

5. Cehajic-Kapetanovic J, Xue K, Martinez-fernandez de la Camara C, et al. Initial results from a first-in-human gene therapy trial on $\mathrm{X}$-linked retinitis pigmentosa caused by mutations in RPGR. Nat Med. 2020;26(3):354-359. doi:10.1038/s41591-020-0763-1

6. Beebe DC, Holekamp NM, Siegfried C, Shui Y-B. Vitreoretinal influences on lens function and cataract. Philos Trans $R$ Soc Lond B Biol Sci. 2011;366(1568):1293-1300. doi:10.1098/rstb.2010.0228

7. Acosta-Rojas ER, Comas M, Sala M, Castells X. Association between visual impairment and patient-reported visual disability at different stages of cataract surgery. Ophthalmic Epidemiol. 2006;13 (5):299-307. doi:10.1080/09286580600694464

8. Comas M, Castells X, Acosta ER, Tuni J. Impact of differences between eyes on binocular measures of vision in patients with cataracts. Eye. 2007;21(6):702-707. doi:10.1038/sj.eye.6702305

9. Ruiz-Mesa R, Abengozar-Vela A, Ruiz-Santos M. A comparative study of the visual outcomes between a new trifocal and an extended depth of focus intraocular lens. Eur J Ophthalmol. 2018;28(2):182187. doi:10.5301/ejo.5001029

10. Mencucci R, Favuzza E, Caporossi O, Savastano A, Rizzo S. Comparative analysis of visual outcomes, reading skills, contrast sensitivity, and patient satisfaction with two models of trifocal diffractive intraocular lenses and an extended range of vision intraocular lens. Graefe's Arch Clin Exp Ophthalmol. 2018;256(10):1913-1922.

11. De Silva SR, Evans JR, Kirthi V, et al. Multifocal versus monofocal intraocular lenses after cataract extraction. Cochrane Database Syst Rev. 2016;12:CD003169. doi:10.1002/14651858.CD003091.pub4

12. Venter JA, Pelouskova M, Bull CE, et al. Visual outcomes and patient satisfaction with a rotational asymmetric refractive intraocular lens for emmetropic presbyopia. J Cataract Refract Surg. 2015;41(3):585593. doi:10.1016/j.jcrs.2014.06.035

13. Oculentis. Oculentis Data Sheet - Competency in Intraocular Surgery; 2011. Available at www.oculentis.com. Accessed October 21, 2019.

14. Plaza-Puche A, Alió J. Lentis Mplus. In: Hoffer K, Savini G, editors. Multifocal Intraocular Lenses: Historical Perspective. Springer, Cham; 2014:235-245.

15. Bausch+Lomb. Cataract - intraocular lenses, Monofocal and Premium - AKREOS ADAPT AO. Available at: www.bauschsurgical.eu/pro ducts/cataract/intraocular-lenses-monofocal-and-premium/akreosadapt-ao/. Accessed June 17, 2020. Accessed November 27, 2019
16. Berrow EJ, Wolffsohn JS, Bilkhu PS, Dhallu S, Naroo SA, Shah S. Visual performance of a new bi-aspheric, segmented, asymmetric multifocal IOL. J Refractive Surg. 2014;30(9):584-588. doi:10.39 28/1081597X-20140814-01

17. Nivean M, Nivean PD, Reddy JK, et al. Performance of a newgeneration extended depth of focus intraocular lens-a prospective comparative study. Asia Pac j Ophthalmol. 2019;8(4):285-289. doi:10.1097/APO.0000000000000245

18. Radner W. Introducing a new reading chart. Ophthalmol Times Eur. 2008;4(2).

19. Roper-Hall G. The "Worth" of the worth four dot test. Am Orthoptic J. 2004;54(1):112-119. doi:10.3368/aoj.54.1.112

20. Karania R, Evans BJ. The mallett fixation disparity test: influence of test instructions and relationship with symptoms. Ophthalmic Physiol Opt. 2006;26(5):507-522. doi:10.1111/j.1475-1313.2006. 00385.x

21. Vancleef K, Read JCA, Herbert W, Goodship N, Woodhouse M, Serrano-Pedraza I. Overestimation of stereo thresholds by the TNO stereotest is not due to global stereopsis. Ophthalmic Physiol Opt. 2017;37(4):507-520. doi:10.1111/opo.12371

22. Tang ST, Evans BJ. The near mallett unit foveal suppression test: a cross-sectional study to establish test norms and relationship with other optometric tests. Ophthalmic Physiol Opt. 2007;27(1):31-43. doi:10.1111/j.1475-1313.2006.00453.x

23. Wang B, Ciuffreda KJ. Depth-of-focus of the human eye: theory and clinical implications. Surv Ophthalmol. 2006;51(1):75-85. doi:10.1016/j.survophthal.2005.11.003

24. Buckhurst PJ, Wolffsohn JS, Gupta N, Naroo SA, Davies LN, Shah $\mathrm{S}$. Development of a questionnaire to assess the relative subjective benefits of presbyopia correction. J Cataract Refract Surg. 2012;38 (1):74-79. doi:10.1016/j.jcrs.2011.07.032

25. Piano MEF, Tidbury LP, O'Connor AR. Normative values for near and distance clinical tests of stereoacuity. Strabismus. 2016;24 (4):169-172. doi:10.1080/09273972.2016.1242636

26. Fawcett SL, Herman WK, Alfieri CD, Castleberry KA, Parks MM, Birch EE. Stereoacuity and foveal fusion in adults with long-standing surgical monovision. J Am Assoc Pediatr Ophthalmol Strabismus. 2001;5(6):342-347. doi:10.1067/mpa.2001.119785
Clinical Ophthalmology

\section{Publish your work in this journal}

Clinical Ophthalmology is an international, peer-reviewed journal covering all subspecialties within ophthalmology. Key topics include: Optometry; Visual science; Pharmacology and drug therapy in eye diseases; Basic Sciences; Primary and Secondary eye care; Patient Safety and Quality of Care Improvements. This journal is indexed on PubMed
Central and CAS, and is the official journal of The Society of Clinical Ophthalmology (SCO). The manuscript management system is completely online and includes a very quick and fair peer-review system, which is all easy to use. Visit http://www.dovepress.com/ testimonials.php to read real quotes from published authors. 